\title{
LINGUAGEM E DIREITO: UMA COMBINAÇÃO INTERDISCIPLINAR?
}

\author{
(Language and law: \\ an interdisciplinary combination?)
}

Fernando Oliveira ${ }^{1}$

(Universidade de Brasília - UnB)

\begin{abstract}
The present literature research encompassed some areas in which language and law intertwine. Hence, the objective was to discuss the interdisciplinary field of language and law and its relationship to disciplines of both law and linguistics. To this end, the philosophy of language and law, law and literature, law and semiotics have suggested an association of both sciences, which has attracted research around the world, especially in the United States and Britain. Furthermore, it explored rhetoric, sociolinguistics, discourse analysis, forensic linguistics to illustrate how these sciences have construed meanings and established power in contemporary society by using language as its platform. Despite the exciting and fruitful relationship of both sciences, the infiltration of this area into the humanities has been suggested as paramount to future linguistic and legal development.
\end{abstract}

Keywords: Language, law, interdisciplinarity.

\section{RESUMO}

A presente pesquisa bibliográfica buscou abranger algumas extensões em que a linguagem e o direito se entrelaçam. Desse modo, pretendeu-se discutir o campo interdisciplinar entre linguagem e direito e sua relação com disciplinas autônomas do direito e da linguística. Para isso, sugeriuse a relação inseparável de disciplinas como a filosofia da linguagem e direito, direito e literatura, direito e semiótica, que despertaram pesquisas pelo mundo, em especial nos Estados Unidos e Grã-Bretanha. Além disso,

1. Doutorando do Departamento de Linguística, Português e Línguas Clássicas da Universidade de Brasília, Mestre em Linguística Aplicada pela Universidade de Birmingham, Reino Unido. 
explorou-se a retórica, a sociolinguística, a análise do discurso, a linguística forense para desvendar como essas ciências têm construído significados $e$ estabelecido poder na sociedade contemporânea, tendo a linguagem como suporte principal para construir essas relações. Apesar da profícua $e$ instigante relação de ambas as ciências, sugere-se a disseminação desse campo das ciências humanas como sendo de suma importância para os fazeres linguístico e jurídico.

Palavras-chave: Linguagem, direito, interdisciplinaridade.

\section{Considerações iniciais}

A história não consegue datar o início do estudo da linguagem e do direito. Entretanto, pesquisadores afirmam que sempre houve uma relação muito próxima entre essas duas áreas, mesmo que ela não tenha sido formalmente reconhecida pela academia ao longo dos anos. Assim, pode-se afirmar que a linguagem pode existir sem o direito, mas este último necessita da primeira para se estabelecer.

Um fato que ajuda a entender essa relação são os relatos obtidos em documentos pré-históricos, visto que algumas pesquisas realizadas revelam que nossos predecessores certamente desenvolveram costumes e algum método de disputa informal para resolver algumas situações de conflito logo no início da história da humanidade, levando-nos a inferir que essas relações de direito se operacionalizavam por meio da linguagem. Além disso, há de se mencionar que a palavra "direito" sugere algo mais formal do que um simples costume. No entanto, neste artigo, pretendeu-se evitar os debates filosóficos e jurisprudenciais que envolvem o termo e como esse se difere de simples costumes.

Pode-se inferir que os seres humanos começaram a fazer uso da linguagem bem antes mesmo de se ter o direito como forma de nortear a convivência em sociedade. Assim, concebê-lo sem a linguagem tornar-se-ia algo impraticável. Por conseguinte, também não se pretende afirmar que a lei deva ser obrigatoriamente escrita. Por um lado, alguns pesquisadores sugerem que o surgimento do direito necessariamente pressupõe a existência da escrita. Sem dúvida alguma, a tecnologia da escrita facilitou a expressão e a comunicação 
das normas legais. Versteeg (2000) destaca o fato de que assim que os Babilônios criaram a escrita, eles já começaram a utilizá-la com propósitos jurídicos. Prova disso é que já escreviam contratos e regras de conduta em pedras de argila.

Por outro lado, tradições e culturas essencialmente orais, como as indígenas, também desenvolveram o direito. Relatos da FUNAI (2005) - Fundação Nacional do Índio sugeria a linguagem escrita como um dos entraves para o estabelecimento dos direitos dos índios quando a demarcação de terras era feita apenas por meio de documento escrito, sendo que, para algumas comunidades indígenas, era necessário que o 'homem branco' declarasse oralmente e em público aquilo que estava escrito no papel como forma de garantia daquilo que no direito estava sendo assegurado às nações indígenas.

Apesar da relação próxima e histórica entre a escrita e a lei, pode-se ponderar que a primeira não é essencial para a existência dessa última. Um exemplo disso é citado nos relatos encontrados a respeito da Islândia medieval que revelam que, uma vez por ano, os moradores se reuniam, vindos de todos os cantos da ilha, para fazer parte do que chamavam de Althing, um tipo de assembleia popular ou parlamento. Esse evento acontecia no chamado Thingvellir, local intermediário entre o plateau europeu e o norte americano. Um dos propósitos principais do Althing era estabelecer disputas.

Para se estabelecer disputas, havia de se ter algumas normas e meios de comunicá-las à população. Também é válido lembrar que naquela época, a Islândia ainda não possuía um código escrito. Segundo documentos históricos, o representante oficial que presidia essas reuniões era o lögsögumadr, ou aquele que falava em nome da lei. Desse modo, todo ano, esse oficial tinha como função recitar de cor para a população um terço das leis da Islândia em Thingvellir. De acordo com Quinn (2000), o corpus inteiro da lei deveria ser recitado em um ciclo de três anos. No final desse período, os escribas escreviam as leis da Islândia que eram ditadas pelo lögsögumadr.

A linguagem é essencial para a lei, uma vez que se pode afirmar que as normas legais devem ser articuladas por meio da linguagem, seja ela escrita ou falada, tendo em vista que toda atividade jurídica, 
seja uma contenda judicial, a escrita de um contrato, uma apelação oral, entre outros, pressupõem a existência de um sistema sofisticado de comunicação, o que nos leva a concluir que tais atividades jurídicas requerem a utilização da linguagem nas duas modalidades correspondentes às culturas oral e escrita.

Assim, a linguagem torna-se essencial para o campo jurídico em pelo menos dois modos - por um lado, as leis ou as normas jurídicas não podem existir sem a habilidade de articulá-las ou descrevê-las por meio da língua, e, por outro lado, a linguagem é elemento essencial para que a realização do direito aconteça. Portanto, há uma relação muito próxima entre essas áreas.

Calmon de Passos (2001, 63-64) declara que,

“[...] O Direito, mais que qualquer outro saber, é servo da linguagem. Como Direito posto é linguagem, sendo em nossos dias de evidência palmar constituir-se de quanto editado e comunicado, mediante a linguagem escrita, por quem com poderes para tanto. Também linguagem é o Direito aplicado ao caso concreto, sob a forma de decisão judicial ou administrativa. Dissociar o direito da Linguagem seria privá-lo de sua própria existência, porque, ontologicamente, ele é linguagem e somente linguagem.”

Embora essa relação seja antiga, não se sabe ao certo quando os estudiosos começaram a pensar sobre ela ou estudá-la. Cerca de 500 anos A.C, um ministro Chinês ordenou que algumas leis deveriam ser escritas em papiros feitos de bronze. Esses papiros se perderam, mas alguns pesquisadores afirmam que eles existiram por causa de uma carta remanescente escrita por um agente do governo chinês. Segundo Bodde \& Morris (1973,16-17), esse oficial se recusou a escrever as leis, porque, segundo ele, as pessoas deixariam de reivindicar seus direitos pela espada e se conformariam com as normas escritas.

$\mathrm{O}$ presente artigo tem como objetivo discutir questões que entrecruzam os campos da linguagem e do direito com vistas a destacar a necessidade de uma disciplina formal que venha a reforçar o diálogo acadêmico-científico interdisciplinar como elemento capaz de fortificar e estabelecer relações comunicativas muito mais 
reflexivas e profícuas nos seus devidos campos de atuação. Para tanto, o presente estudo encontra-se dividido em quatro seções, além desta introdução. A seção 2, da qual nos ocuparemos a seguir, caracteriza os procedimentos da pesquisa documental, bem como os procedimentos para o levantamento e a sistematização dos dados utilizados.

\section{Pesquisa documental: uma disciplina pouco difundida}

Uma vez que a linguagem e o direito estão intimamente ligados, e que as pessoas pensam nessa relação há milênios, questiona-se o fato de muitos estudos interdisciplinares terem se proliferado ao longo dos anos, mas ainda termos uma produção bibliográfica ainda tímida em relação a essas disciplinas.

Essa não é apenas uma impressão subjetiva. Utilizando uma abordagem informal por meio da Linguística de corpus, foi realizada em agosto de 2013 uma pesquisa para saber o número de vezes que a expressão "linguagem e direito" aparece na Internet, utilizando o instrumento de pesquisa GOOGLE. O retorno foi de 26.500 ocorrências. À primeira vista, parece-nos um número significativo, mas, ao colocar a expressão "direito e economia", por exemplo, houve 996.000 ocorrências, demonstrando o fato de que, embora a linguagem seja sem dúvida muito mais importante para o direito, a questão econômica sobrepõe-se. A tabela 1 abaixo ilustra este fato:

\begin{tabular}{|l|l|}
\hline Língua Portuguesa & $\mathrm{N}^{\mathrm{o}}$ de ocorrências \\
\hline Linguagem e Direito & 26.500 \\
\hline Direito e economia & 996.000 \\
\hline
\end{tabular}

Tabela 1: $\mathrm{N}^{\mathrm{o}}$ de ocorrência dos termos no GOOGLE.COM

Já em língua inglesa, a expressão "law and language" obteve 82.200 resultados e "law and economics" surpreendentes 1.600 .000 ocorrências, visualizadas na tabela 2 abaixo: 


\begin{tabular}{|l|l|}
\hline Língua inglesa & $\mathrm{N}^{\mathrm{O}}$ de ocorrências \\
\hline Law and language & 82.200 \\
\hline Law and economics & 1.600 .000 \\
\hline
\end{tabular}

Tabela 2: $\mathrm{N}^{\mathrm{O}}$ de ocorrência dos termos no GOOGLE.COM

Conformedemonstradoacima, existe uma produçãointernacional maior do que a brasileira no tocante aos termos mencionados em termos quantitativos, embora ainda exista uma produção menor para linguagem e direito em nível nacional e internacional, o que corrobora o fato de que a questão econômica tornou-se mais evidente em ambos os casos, levando à prioridade da relação do termo Direito e economia em detrimento do termo Direito e linguagem.

Para ampliar mais a pesquisa e se ter garantia de outros indicadores, o instrumento de busca YAHOO também foi utilizado e a expressão "Linguagem e direito" produziu 29.000 resultados e a expressão "Direito e economia" produziu 905.000 resultados, o que confirma a pouca produtividade do termo "Linguagem e direito", mas com destaque para o aumento da produção "Direito e economia". Portanto, independente do instrumento utilizado, não se observa uma diferença significante entre os indicadores. A tabela 3 abaixo ilustra as ocorrências encontradas no YAHOO.COM:

\begin{tabular}{|l|l|}
\hline Língua Portuguesa & $N^{o}$ de ocorrências \\
\hline Linguagem e Direito & 29.000 \\
\hline Direito e economia & 905.000 \\
\hline
\end{tabular}

Tabela 3: $\mathrm{N}^{\circ}$ de ocorrência dos termos no YAHOO.COM

Também se pesquisou a expressão "Linguística Forense" e houve 16.600 resultados, o que também demonstra uma produção muito pequena em nível nacional, mas que, ao colocar "Forensic Linguistics", houve 125.000 resultados, ou seja, quase 10 vezes mais que a produção nacional, vistos na tabela 4 abaixo: 


\begin{tabular}{|l|l|}
\hline Língua Portuguesa & $\mathrm{N}^{\circ}$ de ocorrências \\
\hline Linguística Forense & 16.600 \\
\hline Forensic Linguistics & 125.000 \\
\hline
\end{tabular}

Tabela 4: $\mathrm{N}^{\circ}$ de ocorrência dos termos no GOOGLE.COM

Um dos principais motivos da disciplina Linguagem e direito ainda ser subestimada se deve ao fato de até mesmo nas faculdades de direito não se encontrar uma disciplina que aborde essa relação. Pelo menos nos Estados Unidos, Inglaterra e no Brasil, parece-nos que advogados e professores de Direito tendem a ver a língua como uma ferramenta, ao invés de um objeto de estudo.

Ressalta-se que advogados costumam ser bons usuários da língua, mas a maioria parece não internalizar os valores associados à fala e à escrita, ou seja, revela uma consciência linguística crítica sobre o uso que dela fazem apenas para acusar ou defender. Além disso, as instituições de ensino superior, no caso as Faculdades de Direito, parecem deixar fora do currículo dos cursos o aprofundamento de estudos da cultural oral (orality) e cultura escrita (literacy), fatores fundamentais para estabelecer relações linguístico-discursivas mais profundas que poderiam ir além da práxis desses profissionais.

Por outro lado, a Internet já começa a mostrar algumas perspectivas mais tangíveis nessa direção. Assim, a busca no Google do grupo nominal "Direito e economia" Law and economics, apareceram diversos cursos oferecidos na maioria das faculdades americanas. Também apareceu um número significativo em relação à "Direito e literatura" Law and literature em algumas universidades. No entanto, ao colocar "linguagem e Direito" language and Law, a pesquisa retornou apenas o curso de direito da Universidade de Brooklyn e a Loyola Law School em Los Angeles. Também se descobriu que o professor David Mellinkoff uma vez lecionou um curso na Universidade da Califórnia que compreendia a relação entre Linguagem e direito, mas, desde a sua morte, não houve mais a oferta da disciplina.

Todavia, pode-se sugerir que a presença de um curso que englobe Linguagem e direito nas universidades americanas não se revela 
muito evidente, pois as escolas de direito não parecem acreditar ser necessária a presença de um especialista em linguagem jurídica no seu corpo docente ou até mesmo conseguem contemplar a possibilidade de oferecer tal disciplina. No Brasil a realidade se demonstra ainda mais crítica, pois pesquisa realizada através do GOOGLE não retornou nenhuma universidade brasileira que contemplasse a relação entre linguagem e Direito. No entanto, observou-se a oferta de aulas de redação sobre escrita jurídica como disciplina obrigatória.

Outro fato é que a ementa dessas aulas preconiza o desenvolvimento de habilidades de escrita de gêneros textuais clássicos utilizados no direito com instruções práticas de como escrever um memorando, uma procuração, uma petição, ao invés de também contemplar a relação existente entre linguagem e direito. Ao observar o currículo Lattes de alguns docentes da área de Direito, também se observou que a grande maioria dos professores que oferece a disciplina de redação jurídica não possui formação em Linguística ou Letras, o que não surpreende o fato de as aulas estarem voltadas apenas para aspectos técnicos da escrita de documentos legais ao invés de também focar como a linguagem pode operacionalizar os mecanismos da escrita jurídica. Vale ressaltar que, para esse estudo, preferi, por questões éticas, não mencionar o nome das faculdades pesquisadas.

\section{A linguagem jurídica}

Pesquisadores nos Estados Unidos e Inglaterra fizeram várias pesquisas a respeito da linguagem jurídica e como ela se difere da linguagem comum, seja escrita ou falada. No entanto, a maioria da literatura encontrada enfoca a linguagem escrita. Um estudo clássico na área é o de Mellinkoff (1963). Tiersma (1999) também concentrou seus estudos na linguagem escrita, embora também se encontre alguma produção a respeito da linguagem jurídica oral.

Quando se fala em uso e estilo, Garner (2009) tornouse referência nos Estados Unidos com seu famoso Black's Law 
Dictionary, no qual ele introduziu princípios modernos de lexicografia nas edições recentes do dicionário e que até hoje permeiam a escrita jurídica americana. Embora a maioria dos linguistas veja a produção de Garner com certa restrição justamente pelo fato de seu trabalho ser mais prescritivo, ele, sem dúvida alguma, conseguiu fazer uma coletânea bastante significativa referente ao uso da linguagem jurídica.

Wydick (1994) trouxe sua contribuição ao encabeçar o movimento para tornar a linguagem jurídica mais compreensível, especialmente no que diz respeito aos documentos destinados ao público em geral em relações que envolvem consumo tais como contratos, financiamentos, manuais de produtos, rótulos, entre outros.

Tal movimento também levou várias cortes nos Estados Unidos, sobretudo na Califórnia, a adotar uma linguagem mais simples e de fácil compreensão aos jurados e ao público em geral, com instruções com menos termos técnicos e mais diretas, sem o exagero no uso de termos jurídicos (Tiersma, 1996).

\subsection{A linguagem e o Direito}

O conhecimento linguístico certamente pode trazer uma compreensão maior a respeito da natureza ou do conteúdo do direito, mas algumas áreas do direito ainda apresentam alguma dificuldade em reconhecer essa importância. Ainsworth (1993), Solan \& Tiersma (2005) apontam para o fato de que a área criminal já demonstra algum progresso nesse sentido. Em artigo publicado no Yale Law Journal em 1993, Ainsworth explica linguisticamente que, quando um policial é interrogado durante um julgamento, a relação de poder e as escolhas lexicais feitas por ele passam mais segurança para os jurados do que o depoimento de uma testemunha comum.

A constituição brasileira, no Artigo $5^{\circ}$ inciso IX, garante o direito de expressão, mas será que essa expressão inclui apenas enunciados verbais ou também poder-se-iam englobar expressões não verbais que, de certa forma, também comunicam? Por outro lado, os enunciados não verbais que revelam ameaça ou uma fala desrespeitosa também 
entrariam no direito à expressão ou poderiam ser classificados enquanto uma conduta repreensível não amparada pelo direito de expressão? No entanto, há debates intensos nesse sentido, que encontram amparo nos recursos utilizados pela teoria e filosofia da linguagem defendidos por Greenawalt (1989), Haiman (1993) e Tiersma (1993). Além disso, em relação a essas questões, o próprio STF (Superior Tribunal Federal) - (cf. CUNHA E CRUZ, 2011) também já vislumbra dar respostas a esses questionamentos que, sem dúvida alguma, passam pela questão da linguagem.

Segundo Megarry $(1958,25)$ a área da hermenêutica jurídica sofreu grande influência da linguística, especialmente na interpretação de Estatutos, levando até alguns juízes como Baron Pollock, nos Estados Unidos, a afirmar que "os juízes são filologistas da mais alta ordem”. Que os juízes são realmente filologistas é um assunto ainda a se debater, mas o fato é que a partir dessa afirmação, eles passaram a prestar mais atenção na linguagem, especialmente quando o princípio interpretativo da regra literal estava em voga nos Estados Unidos. Essa regra dizia que os juízes deveriam determinar o significado de um texto jurídico fora do seu contexto, sem considerar as evidências fora do mesmo. Assim, sem levar em consideração evidências extrínsecas ao texto, os juízes desenvolveram cânones ou máximas de interpretação para ajudá-los a compreender os significados difíceis ou ambíguos que ocorriam na língua.

Algumas dessas máximas, incluindo expressio unius e ejusdem generis foram estabelecidas para refletir as regras da linguagem comum, ao invés de ordenar princípios jurídicos. No entanto, esses cânones da interpretação sofreram muitas críticas nas últimas décadas. Ao menos dois especialistas em linguagem jurídica, dentre eles Sinclair (1985) e Miller (1990), utilizando as ferramentas da pragmática, e mais especificamente Grice (1989) demonstraram que a noção de implicaturas conversacionais revelam que os cânones textuais, na verdade, são generalizações de cunho linguístico a respeito da linguagem.

Outra abordagem promissora na área da interpretação jurídica é a da linguística cognitiva, ou das ciências cognitivas. 
Solan (1998) e Winter (2001) possuem trabalhos nesse sentido. Contudo, abordagens que utilizam a hermenêutica para interpretar a linguagem de Estatutos não é o único caminho para se compreender a linguagem jurídica, visto que há muitas considerações não linguísticas que devem ser levadas em conta antes de se entender ou aplicar um Estatuto. Desse modo, à medida que esperamos que os juízes façam a aplicação da lei, e, à medida que essas intenções são expressas por meio da linguagem, as abordagens linguísticas que levam ao significado - que não são apenas abstrações teóricas, mas observações de como as pessoas realmente utilizam a língua - são extremamente relevantes nesse processo.

Desse modo, alguns especialistas do direito estão começando a perceber que a linguística pode ser útil no entendimento da interpretação jurídica, mas poucos possuem a formação linguística necessária para colocar isso em prática. Existem relatos históricos que dizem que muitos especialistas da área jurídica passaram a estudar os fundamentos da teoria econômica para poderem atuar da melhor forma no direito. Talvez, agora, seja o momento para os acadêmicos da área jurídica começarem a aprender alguns princípios básicos da linguagem, sobretudo quando os mesmos se consideram especialistas em uma área específica do direito, como a interpretação jurídica, na qual um conhecimento linguístico mais sofisticado pode ser especialmente profícuo.

Entretanto, é difícil prever se a tendência crescente da linguística em compreender questões jurídicas irá realmente ampliar o campo da linguagem e do direito. Alguns especialistas da área, que ainda representam um pequeno número, consideram que os mesmos não estão envolvidos na prática da linguagem e do direito. Ao contrário, eles se consideram especialistas na escrita jurídica ou em direito criminal ou constitucional. Contudo, existem alguns poucos acadêmicos que afirmam ser especialistas em linguagem e direito, mas até que essa situação mude, esse campo ainda permanecerá uma área ainda a ser disseminada. 


\section{O campo de atuação da linguagem e direito}

Nesta seção e nas próximas subseções, fez-se um levantamento a respeito das áreas de estudo e pesquisa que podem ser consideradas na vasta área de atuação que compreende a linguagem e o direito. A intenção é mencionar alguns dos trabalhos principais a fim de se ter uma visão geral do que tem sido feito. Aqueles que quiserem uma lista mais ampla, sugere-se a consulta de Levi (1994) ou mesmo a bibliografia que pode ser encontrada online no sítio da Associação Internacional de Linguistas Forenses em www.iafl.org.

\subsection{Direito e filosofia da linguagem}

Há grande interesse por parte de filósofos e acadêmicos da área do direito em relação à aproximação da filosofia e do direito, conhecido como jurisprudência. Assim, a filosofia da linguagem, mais especificamente a teoria dos atos de fala, provavelmente seja o aspecto da filosofia mais relevante para a linguagem e o direito. Um exemplo da aplicação da teoria dos atos de fala ao sistema jurídico encontra-se nos trabalhos de Kurzon (1986). No entanto, o que se torna mais importante para a jurisprudência é a natureza do direito, embora essa seja uma discussão um tanto quanto filosófica. Mas, quando os filósofos olham de forma mais atenta para a linguagem na qual as leis são expressas, a discussão pode se tornar mais linguística do que jurídica, especialmente ao se colocar questões tais como - a lei é um comando de um soberano para a população em geral, ou ela consiste em declarações ou uma série de normas para que os juízes possam decidir a respeito dos casos? Em outras palavras, qual é o tipo de ato de fala que é a lei? Existe uma vasta literatura a respeito de abordagens filosóficas na interpretação jurídica. Bix (1993), por exemplo, apresenta uma boa introdução à interpretação jurídica do ponto de vista filosófico. 


\subsection{Direito e literatura}

O campo de direito e literatura é certamente vasto. Um livro que se tornou um divisor de águas na produção intelectual americana é o de Richard Posner, renomado juiz americano que escreveu em 1988 um livro cujo título é Law and Literature, no qual ele faz colocações a respeito da relação mal compreendida entre literatura e direito. Outro autor que se destaca na área é Fish (1989) que se dedica à escrita jurídica e à interpretação literária. No entanto, a maioria dos trabalhos em direito e literatura parecem girar em torno da análise literária dos textos jurídicos e como a teoria literária pode ser relevante para problemas de interpretação jurídica. Também foi encontrada uma produção bastante significativa realizada por Christine Alice Corcos (2000) com mais de 1000 páginas que listam livros e artigos a respeito do tópico. A pesquisa retornou que atualmente existem mais de 30.000 livros e artigos produzidos que tratam de direito e literatura. Contudo, de todos os trabalhos produzidos nesta área, os que mais têm relação com a linguagem são aqueles que comparam as teorias de interpretação jurídica e literária, que incluem questões de intenção do autor e o papel do público em geral frente a questões jurídicas.

\subsection{Direito e semiótica}

Outra disciplina que pode ser considerada parte do vasto campo de pesquisa é a que engloba semiótica e direito. O International Journal for the Semiotics of Law, também conhecido no mundo franco-falante como Revue Internationale de Sémiotique Juridique, apresenta um artigo interessante a respeito dessa relação. $\mathrm{O}$ jornal é importante porque traz as áreas de pesquisa que são consideradas parte da disciplina, que compreendem, por exemplo, as diferentes formas de análise textual nos discursos utilizados no direito. Mais especificamente, refere-se à abordagem semiótica de Greimas, Peirce e Lacan, abordando assuntos que também envolvem retórica, filosofia da linguagem, sociolinguística e desconstrução. Embora algumas abordagens sejam mais relevantes do que outras para tentar entender 
os 'discursos do direito', todas elas estão relacionadas de uma forma ou de outra à linguagem e direito.

\subsection{Direito e retórica}

A retórica e o direito podem ser considerados como uma categoria do vasto campo entre linguagem e direito. A retórica, por sua vez, tem sido estudada desde os tempos clássicos e sua teoria foi colocada em prática nos tribunais durante esse período, em especial por Cícero. Alguns trabalhos sobre retórica jurídica incluem o de Peter Goodrich (1987) e Austin Sarat e também o de Sarat \& Kearns (1994). Há uma vasta bibliografia que foi escrita por advogados para advogados no tocante ao uso da linguagem como ferramenta persuasiva. À medida que esses trabalhos focam recursos linguísticos, parece-nos que o estudo da retórica e do direito se coadunam perfeitamente com a área de direito e linguagem.

\subsection{Direito, análise do discurso e sociolinguística}

A análise do discurso e a sociolinguística são áreas que vêm sendo utilizadas para esclarecer alguns aspectos da área jurídica. Há um estudo bastante promissor e crescente a respeito das estratégias discursivas que ocorrem em tribunais, geralmente envolvendo a análise da interação entre os profissionais da área jurídica e os cidadãos comuns durante os julgamentos. Cito como exemplo os trabalhos de Janet Cotterill (2003) no estudo que ela fez do julgamento mundialmente conhecido no caso O.J. Simpson. Também há outros estudos como o de Greg Matoesian (2001) no julgamento por estupro de William Kennedy Smith, além do livro de Susan Ehrlich (2001) sobre o caso de estupro que aconteceu em um campus de uma universidade americana, a análise de julgamentos civis feito por Gail Stygall (1994), o estudo etnográfico de John Conley e William O’Barr (1990) que discorre como os profissionais do direito utilizam a língua como uma ferramenta de poder e dominação. 


\subsection{Direito e linguística forense}

As possibilidades de atuação da linguística forense são muito vastas, mas, ao mesmo tempo, pouco conhecidas. No entanto, sabese que se refere ao uso do conhecimento linguístico e metodologias para resolver questões que são cruciais no mundo jurídico, que levam em consideração a interface entre linguística e direito, na sua acepção mais ampla, ou ao uso de análises linguísticas para o fornecimento de evidências no contexto criminal e judicial, em casos mais restritos. Desse modo, já se tem utilizado essa ciência para resolver questóes de identidade, autoria de textos, ou até mesmo a origem social de uma pessoa. Além disso, é possível caracterizar as particularidades da fala de um indivíduo e definir os parâmetros conversacionais utilizados pelo falante para se obter um tipo de 'impressão digital' da fala.

Embora questões de identidade sejam um campo importante na atuação da linguística forense, quaisquer questões que envolvam direito e linguagem podem ser analisadas por meio dessa ciência. Shuy (1993) discute diversos casos no qual ele pôde analisar o significado e o conteúdo de enunciados feitos em gravações obtidas pela polícia ou agentes do governo. Na Inglaterra, Coulthard (2002) conduziu análises para verificar a autenticidade de algumas confissões escritas que envolviam casos criminais.

Todavia, o grande desafio da linguística forense é dar credibilidade aos resultados encontrados. Eades (2005), Solan e Tiersma (2005) questionam até que ponto os resultados e as conclusões feitas por meio da análise linguística ao se utilizar ferramentas e softwares para resolver questões de autoria, sobretudo quando se tem apenas um pequeno trecho escrito são válidos.

Alguns autores como Gibbons (2003) sugerem que o termo 'linguística forense' deveria ser empregado mais amplamente, como um sinônimo para o termo 'direito e linguagem'. Tiersma (2005) já considera que a linguística forense deveria ser uma subárea do termo maior "linguagem e direito". Nesse sentido, há dois problemas em se utilizar o termo 'linguística forense' para se referir à linguagem e ao direito no seu sentido mais amplo. Por um lado, o termo 'forense', 
no contexto jurídico, geralmente refere-se a pessoas ou organizações voltadas para a resolução de crimes. Assim, o termo poderia ser utilizado para se referir a esforços científicos para se resolver qualquer tipo de disputa legal, o que, de certa forma, não se refere à análise das leis ou do sistema legal de forma mais ampla, ou ao estudo da linguagem jurídica.

Por outro lado, o termo 'linguística' também apresenta outra questão - embora o termo possa ser entendido como o estudo de qualquer aspecto da linguagem, na verdade há uma tendência de se identificar a linguística a áreas mais tradicionais de estudo que geralmente estão associadas aos trabalhos de Leonard Bloomfield, Roman Jacobson e Noam Chomsky. Por conseguinte, estudiosos da relação entre direito e literatura, ou direito e semiótica, ou direito e filosofia da linguagem, por exemplo, talvez não se considerem parte desta grande tradição linguística.

Enfim, a linguística forense é uma parte muito importante dentro do vasto campo que estuda a relação entre direito e linguagem, como entende a Associação Internacional de Linguística Forense, e o jornal internacional de Discurso, Linguagem e Direito, embora o termo não seja sinônimo da disciplina linguagem e Direito.

\section{Considerações finais}

O presente artigo não pretendeu esgotar as possibilidades da vasta relação entre linguagem e direito, mas apenas apontar alguns caminhos que alguns pesquisadores ao redor do mundo vêm percorrendo para disseminar a importância de pesquisas que compreendem essa relação. Todavia, ainda resta a indagação dos motivos que ainda levam essa disciplina a não ser tão difundida e fazer parte do currículo das universidades do Brasil e do mundo. Entretanto, a grande maioria dos acadêmicos que se preocupam com a emergência de se estabelecer linguagem e direito como disciplina possui formação em Letras e Direito, ou são pesquisadores dessas disciplinas que se juntaram para realizar pesquisas nessa direção, conforme vimos em Conley e O’Barr (1990). Contudo, algumas iniciativas vêm sendo 
tomadas, como a realização do primeiro congresso internacional de linguagem e direito a ser realizado no Brasil em dezembro de 2013, organizado juntamente pela ALIDI (Associação de Linguagem e Direito dos Países de Língua Portuguesa e pela IAFL (International Association of Forensic Linguists), a ser sediado na UFSC.

Recebido em: julho de 2013 Aprovado em: setembro de 2013

fcezaroliveira@uol.com.br

\section{Referências bibliográficas}

AINSWORTH, Janet. In a different register. The pragmatics of powerlessness in police interrogation. Yale Law Journal 103:259, 1993.

BIX, Brian. Law, language, and legal determinacy. Oxford: Charendon Press, 1993.

BODDE, Derk, and Clarence MORRIS. Law in imperial China. Philadelphia: University of Pennsylvania Press, 1973.

BRASIL. Constituição (1988). Constituição [da] República Federativa do Brasil. Brasília, DF: Senado Federal.

BRYAN, A. Garner. Black's Law Dictionary. 9th ed. West Group, 2009.

CALMON DE PASSOS, J.J. Instrumentalidade do processo e devido processo legal. Revista de processo, v. 102, São Paulo, 2001.

CONLEY, John M., and William M. O’Barr. Rules versus relationships: The ethnography of legal discourse. Chicago: University of Chicago Press, 1990.

CORCOS, Christine Alice. An international guide to law and literature. Buffalo, N.Y.: William S. Hein \& Co., 2000.

COTTERILL, Janet. Language and power in court: A linguistic analysis of the O.J. Simpson trial. Houndmills: Palgrave, 2003.

COULTHARD, Malcom. Whose voice is it? Invented and concealed dialogue in written records of verbal evidence produced by the police. Language in the legal process 19 (Janet Cotterill ed.). Houndmills: Palgrave, 2002. 
CUNHA E CRUZ, Marco Aurélio Rodrigues da. A evolução conceitual da liberdade de expressão na jurisprudência do Supremo Tribunal Federal. Espaço Jurídico, v. 11, p. 402-421, 2011.

EADES, Diana. Applied linguistics and language analysis in asylum seeker cases. Applied Linguistics 26:503-526, 2005.

EHRLICH, Susan. Representing rape: Language and sexual consent. London: Routledge, 2001.

FISH, Stanley. Doing what comes naturally: Change, rhetoric, and the practice of theory in literary and legal studies. Durham: Duke University Press, 1989. FUNAI. Legislação indigenista brasileira. $3^{a}$ edição. Brasília: FUNAI/ CGDOC, 2005.

GIBBONS, John. Forensic linguistics: An introduction to language in the justice system. Oxford: Blackwell Publishing, 2003.

GOODRICH, Peter. Legal discourse: Studies in linguistics rhetoric and legal analysis. London : Macmillan, 1987.

GREENAWALT, Kent. Speech, crime, and the uses of language. Oxford: University Press, 1989.

GRICE, H.P. Logic and conversation. Studies in the way of words, 22-40. Harvard: University Press, 1989.

HAIMAN, Franklyn S. "Speech acts" and the First Amendment. Chicago: University press, 1993.

KURZON, Dennis. It is hereby performed: Legal speech acts. Amsterdam: John Benjamins, 1986.

LEVI, Judith. Language and the law: A bibliographic guide to social science research in the U.S.A. Chicago: American Bar Association, 1994.

MATOESIAN, Gregory. Law and the language of identity: Discourse in the William Kennedy Smith rape trial. Oxford: University Press, 2001.

MEGARRY, R.E. Miscellany-at-law: A diversion for lawyers and others. London: Stevens and Sons, 1958.

MELLINKOFF, David. The language of the law. London: Little, Brown \& Co., 1963.

MILLER, Geoffrey P. Pragmatics and the maxims of interpretation. Wisconsin Law Review, 1990:1179. 
POSNER, Richard. Law and literature: A misunderstood relation. Harvard: University Press, 1988.

QUINN, Susan. From orality to literacy in medieval Iceland. Old Icelandic literature and society 30 (Margaret Clunies Ross ed.). Cambridge: University Press, 2000.

SARAT, Austin, and Thomas b. Kearns (eds). The rhetoric of law. Ann Arbor: University of Michigan Press, 1994.

SHUY, Roger. Language crimes: The use and abuse of language evidence in the courtroom. Oxford Blackwell, 1993.

SINCLAIR, M.B. W. Law and language: The role of pragmatics in statutory interpretation. University of Pittsburgh Law Review 46:373, 1985.

SOLAN, Lawrence M. The language of judges. Chicago: University of Chicago Press, 1993.

. Law, Language and lenity. William \& Mary Law Review 40:57, 1998.

. And Peter Tiersma. Speaking of crime: The language of criminal justice. Chicago: University Press, 2005.

STYGALL, Gail. Trial language: Differential discourse processing and discursive formation. Amsterdam: John Benjamins, 1994.

TEXAS Law Review. Symposium: Law and literature. University of Texas Law Review 60:373-586, 1982.

TIERSMA, Peter. Nonverbal communication and the freedom of "speech". Wisconsin Law review, 1993: 1525-1589.

.Legal language. Chicago: University of Chicago Press, 1999.

. The new Black's. Journal of Legal Education, 55:386, 2005.

2006 .

. Toward more understandable jury instructions. Criminal Justice, 21:4,

VERSTEEG, Russ. Early Mesopotamian law. Durham: Carolina Academic Press, 2000.

WINTER, Steven L. A clearing in the forest: Law, life, and mind. Chicago: University of Chicago Press, 2001.

WYDICK, Richard. Plain English for lawyers (third edition). Durham: Carolina Academic Press, 1994. 